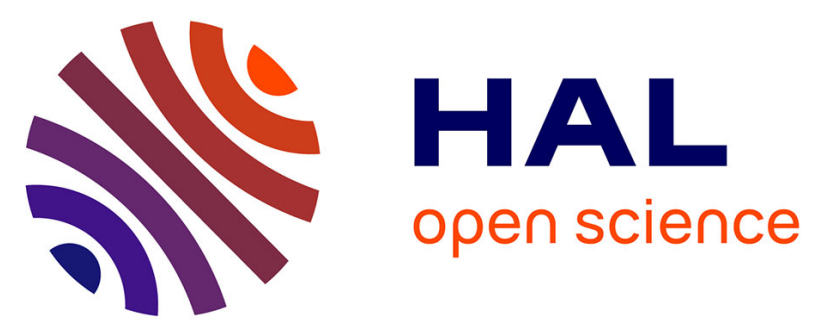

\title{
Evaluation of liver failure in a pediatric transplant recipient of a liver allograft with inherited chromosomally integrated HHV-6B
}

Pascale Bonnafous, Tuan L Phan, Ryan Himes, Karen Eldin, Agnès Gautheret-Dejean, Bhupesh K Prusty, Henri Agut, Flor M Munoz

\section{To cite this version:}

Pascale Bonnafous, Tuan L Phan, Ryan Himes, Karen Eldin, Agnès Gautheret-Dejean, et al.. Evaluation of liver failure in a pediatric transplant recipient of a liver allograft with inherited chromosomally integrated HHV-6B. Journal of Medical Virology, 2019, 10.1002/jmv.25600 . hal-02340227

\section{HAL Id: hal-02340227 \\ https://hal.sorbonne-universite.fr/hal-02340227}

Submitted on 30 Oct 2019

HAL is a multi-disciplinary open access archive for the deposit and dissemination of scientific research documents, whether they are published or not. The documents may come from teaching and research institutions in France or abroad, or from public or private research centers.
L'archive ouverte pluridisciplinaire HAL, est destinée au dépôt et à la diffusion de documents scientifiques de niveau recherche, publiés ou non, émanant des établissements d'enseignement et de recherche français ou étrangers, des laboratoires publics ou privés. 
4 Pascale Bonnafous $^{1 *}$, Tuan L. Phan ${ }^{2}$, Ryan Himes ${ }^{3}$, Karen Eldin ${ }^{3}$, Agnès Gautheret-Dejean ${ }^{4,5}$,

\section{Evaluation of Liver Failure in a Pediatric Transplant Recipient of a Liver} Allograft with Inherited Chromosomally Integrated HHV-6B (iciHHV-6B)
${ }^{1}$ Sorbonne Université, INSERM, Institut Pierre Louis d'Épidémiologie et de Santé Publique (IPLESP), THERAVIR Team, F75013, Paris, France

${ }^{2}$ Department of Microbiology and Immunology, Tulane University School of Medicine, New Orleans, LA, USA; HHV-6 Foundation, Santa Barbara, CA, USA

${ }^{3}$ Baylor College of Medicine and Texas Children's Hospital, Departments of Pediatrics, Molecular Virology and Microbiology, Hepatology, and Pathology, Houston, Texas, USA ${ }^{4}$ AP-HP, Hôpitaux Universitaires Pitié Salpêtrière-Charles Foix, Service de Virologie, Paris, France

${ }^{5}$ Sorbonne Paris Cité, Université René Descartes, Faculté de Pharmacie, Laboratoire de Microbiologie UMR-S 1139, Paris, France

${ }^{6}$ Institute for Virology and Immunobiology, Versbacher Str. 7, Wuerzburg, Germany 18

*Corresponding authors. Mailing addresses:

Pascale Bonnafous, PhD

Equipe "Therapeutic strategies for HIV infection and associated viral diseases"

Institut Pierre Louis d'Epidémiologie et de Santé Publique - UMRS 1136

Sorbonne Université, Faculté de médecine,

Laboratoire de Virologie, bâtiment CERVI, 5ème étage

Hôpital Pitié-Salpêtrière 
1 83, Boulevard de l'Hôpital

275651 Paris cedex 13 France

$3 \quad$ Tel: +33142177418

$4 \quad$ Fax: +33142177411

$5 \quad$ Email : pascale.bonnafous-ext@aphp.fr

$6 \quad$ P. Bonnafous http://orcid.org/0000-0001-5528-9356

7

$8 \quad$ Key words

9 iciHHV-6; horizontal transmission; liver transplantation

\section{Abbreviations}

12 AE, amplification efficiencies; BID, bis in die; Ct, cycle threshold; FCS, fetal calf serum;

13 FFPE, formalin fixed paraffin embedded; iciHHV-6, inherited chromosomally integrated 14 human herpesvirus 6; IFA, immunofluorescence assay; PBS, phosphate buffered saline; 15 ddPCR, droplet digital polymerase chain reaction; qPCR, quantitative real-time PCR; SNP, 16 single nucleotide polymorphism; R, relative quantification ratio; RT, retrotranscription

18 Conflict of Interest Declaration: The authors declare no conflicts of interest in the field of 19 this manuscript.

21 Funding: This work was supported in part by funding from the Association pour la 22 Recherche sur les Infections Virales (ARIV) and by the HHV-6 Foundation.

24 All authors approved the version to be published and agreed to be accountable for all aspects 25 of the work. 


\section{$1 \quad$ Abstract}

2 Background: Active infections of human herpesvirus 6B (HHV-6B) are frequent in

3 immunocompromised recipients after transplantation. Nevertheless, they need to be

4 distinguished from latent inherited chromosomally integrated genomes (iciHHV-6) present in

5 about $1 \%$ of the population, to avoid unnecessary administration of toxic antivirals.

6 Methods: A 5-year-old child presented with acute liver allograft rejection associated with

7 HHV-6 DNA in plasma, which led to an unfavorable outcome. We investigated the possibility

8 of HHV-6 infection derived from an iciHHV-6 present in the donor's liver using molecular

9 and histopathology studies in various tissues, including quantification of HHV-6 DNA,

10 genotyping, sequencing for antiviral resistance genes, relative quantification of viral

11 transcripts and detection of $\mathrm{gB}$ and $\mathrm{gH}$ viral proteins.

12 Results: The presence of iciHHV-6B was evidenced in the donor with signs of reactivation in 13 gallbladder and transplanted liver (detection of HHV-6B mRNA and late proteins). This 14 localized expression could have played a role in liver rejection. Low viral loads in the 15 recipient's plasma, with identical partial U39 sequences, were in favor of viral DNA released 16 from the transplanted liver rather than a systemic infection.

17 Conclusions: Determination of iciHHV-6 status before transplantation should be considered 18 to guide clinical decisions such as antiviral prophylaxis, viral load monitoring, and antiviral 19 therapy. 


\section{INTRODUCTION}

2 Human herpesvirus 6 (HHV-6), which encompasses two distinct species HHV-6A and HHV-

$36 \mathrm{~B}$, is a ubiquitous virus with a seroprevalence greater than $90 \%$ in adults. It establishes

4 lifelong latency in a wide range of cell types, including lymphocytes and hepatocytes, and can

5 reactivate in both immunocompromised and immunocompetent patients, leading to various

6 clinical disorders. ${ }^{1,2}$ HHV-6B accounts for most HHV-6 reactivations, ${ }^{2}$ which usually result

7 from immunosuppressive regimens in the transplant setting. Clinically significant HHV-6

8 infections are treated with ganciclovir, cidofovir, or foscarnet along with a reduction in

9 immunosuppression, which often results in favorable outcome if administered in a timely

10 manner. $^{2}$

11 In addition to this conventional herpesvirus latency, about $1 \%$ of the human 12 population harbors inherited chromosomally integrated HHV-6 genome (iciHHV-6), present 13 in all somatic and germ cells and vertically transmitted in a Mendelian manner. ${ }^{1.3}$

14 Consequently, viral loads in biological samples from these individuals are persistently high 15 and may be mistaken as severe viral reactivation, leading to unnecessary, prolonged and 16 potentially harmful treatments, due to toxicity of conventional HHV-6 antivirals. The

identification of iciHHV-6 can usually be determined by quantitative PCR assays on whole blood. Viral loads that exceed $5.5 \log _{10}$ copies/mL sample in several sequential cellular samples or $\geq 1$ HHV-6 genome/cell can indicate iciHHV-6 status, which can be confirmed by the detection of HHV-6 DNA using qPCR or ddPCR in nail clippings or hair follicles. ${ }^{3}$ The species distinction is made by specific $\mathrm{qPCR}$, restriction fragment length polymorphism (RFLP) or sequencing. In North American individuals including blood donors, the prevalence is estimated to be $0.24 \%$ for iciHHV-6A and $0.40 \%$ for iciHHV-6B. ${ }^{4-6}$ Frequencies are similar in Asian population whereas they vary by geographical location in Europe, reaching $2.8 \%$ for iciHHV-6B in Scotland. ${ }^{4,7-9}$ A case report of an infant with iciHHV-6A and X- 
1 linked severe combined immunodeficiency demonstrated, using methods other than the

2 measurement of viral DNA load, that iciHHV-6 can reactivate and cause disease. ${ }^{10}$

3 Interpretation of significant viral loads can be difficult in immunocompromised patients with

4 iciHHV-6 and the relevance of antiviral treatment has to be considered in light of clinical

5 symptoms.

The transmission of iciHHV-6 from donor to recipient has been described in

7 hematopoietic stem cell transplantation (HSCT), without frequent associated symptoms,

8 except a 1.7-fold increased relative risk of acute graft versus host disease. ${ }^{6,11}$ We previously

9 described the apparent horizontal transmission and reactivation of iciHHV-6A in a liver

10 allograft. ${ }^{12}$ Herein we present a case of possible HHV-6 reactivation of an iciHHV-6B+

11 transplanted liver that was followed by acute rejection in a pediatric patient. The role of

12 HHV-6 infection, whether localized or systemic, was also investigated.

14 MATERIALS AND METHODS

\section{Case report}

A 5-year-old patient received a cadaveric liver allograft due to fulminant liver failure of unknown etiology. His initial diagnostic evaluation for liver failure included negative or normal results for hepatitis $\mathrm{A} / \mathrm{B} / \mathrm{C}$ serology, total $\mathrm{IgG}$, anti-liver-kidney microsomal antibodies, anti-actin antibodies, ceruloplasmin and 24-hour urine copper, alpha-1 PI type, and PCR-based testing for adenovirus, CMV, EBV, HSV, and HHV-6/7/8 viremia. No HHV6 serology was done prior to transplant but three months after transplantation, a positive HHV-6 IgG (2.82 g/L) was documented (IgM was not evaluated). His clinical course was unremarkable until 17 months post-transplantation when he presented with right upper quadrant abdominal pain, diarrhea, dark urine and acholic stools. Laboratory findings were consistent with conjugated hyperbilirubinemia $(1.3 \mathrm{mg} / \mathrm{dL})$ and elevation of transaminases 
1 (AST 1509 U/L, ALT 1939 U/L, GGT 328 U/L). The level of tacrolimus was within

2 therapeutic range. Liver biopsy showed moderate acute cellular rejection, a large lymphoid

3 follicle in one portal tract and patchy subacute lobular necrosis with mild portal and

4 perisinusoidal fibrosis. He had no previous history of rejection. An extensive diagnostic

5 evaluation detected HHV-6 by PCR in plasma $\left(4.7 \times 10^{3}-1.4 \times 10^{4}\right.$ copies $\left./ \mathrm{mL}\right)$ as well as in

6 liver tissue $\left(3.0 \times 10^{2}-1,1 \times 10^{3}\right.$ copies $/ 10^{3}$ Eq cells) (Viracor Eurofins, Missouri, USA) (Table

7 1). Serologic and molecular (blood and/or liver tissue) laboratory results were negative for

8 other infections) including hepatitis A, B, and C, CMV, EBV, VZV, HSV, HHV-7, HHV-8,

9 parvovirus B19, enterovirus and HIV. Blood and liver tissue cultures were negative for

10 bacterial, mycobacterial, and fungal infections. Respiratory samples were negative for

11 influenza virus, respiratory syncytial virus, parainfluenza virus, and adenovirus. Positive

12 serology for HHV-6 three months post-transplant made primary infection an unlikely

13 diagnosis. HHV-6 IgG tested during this admission were $7.99 \mathrm{~g} / \mathrm{L}$, and $\mathrm{IgM}$ were negative.

14 Antiviral therapy was initiated with intravenous ganciclovir (5 mg/Kg/dose BID), but

15 discontinued after one week due to rising HHV-6 viral load. Foscarnet ( $60 \mathrm{mg} / \mathrm{Kg} /$ dose every

168 hours) was administered for 7 days, without response. After hospital discharge, oral

17 valganciclovir (16 mg/Kg/dose BID) was administered for 10 weeks, but liver enzymes and

18 HHV-6 viral load remained elevated. Concomitant treatment for acute rejection consisted of

19 two 5-day pulses of methylprednisolone, addition of mycophenolate, and optimization of

20 tacrolimus and prednisone. A regimen of tacrolimus, mycophenolate, and corticosteroids was

21 maintained for the management of rejection over several months. Despite modest transient

22 improvements of liver function, subsequent liver biopsies demonstrated persistent acute

23 cellular rejection along with new ductopenia, development of micronodular cirrhosis, and

24 eventually complete loss of bile ducts with marked cholestatic hepatocyte injury and cirrhosis,

25 thus the patient was listed for re-transplantation. HHV-6 viral load remained positive both in 
1 plasma and liver throughout the following 19 months, ranging from $10^{2}$ to $3.2 \times 10^{4}$

2 copies/mL plasma and from $1.5 \times 10^{4}$ to $1.7 \times 10^{4}$ copies/mg tissue (units changed by Viracor

3 Eurofins) (Table 1), prompting suspicion that the liver allograft might have been from an

4 iciHHV-6+ donor. Unfortunately, no other compatible graft was available and the patient died

536 months post-transplantation. Post-mortem examination revealed sequelae related to end

6 stage liver disease and the liver allograft demonstrated chronic rejection with ductopenia and

7 vascular changes. This poor evolution, despite the administration of antiviral therapy, led us

8 to explore several hypotheses to explain the fatal outcome: horizontal transmission and/or

9 reactivation of a HHV-6 community-acquired strain, resistance to antiviral drugs, presence of

10 inherited chromosomally integrated HHV-6 (iciHHV-6) in the recipient or the donor with

11 possible reactivation due to immunosuppression.

12

Detection of HHV-6 DNA in hair follicles

14 HHV-6 PCR was performed using DNA extracted from the recipient's hair follicles 15 (Bioworld Consulting Laboratories, Maryland, USA).

\section{Quantification of HHV-6 viral load and HHV-6 genotyping}

18 During clinical course and post-mortem, the viral loads were quantified by Viracor Eurofins and expressed in copies/mL of plasma, copies $/ 10^{3} \mathrm{Eq}$ cells into liver biopsies (at month 17) or copies/mg of tissue (liver biopsies at month 21 and month 36 post-mortem, spleen and lymph nodes post-mortem) (Table 1). Selected tissues were collected from the recipient and donor for further investigations in French and German laboratories: samples of whole blood and

23 corresponding plasma (one and three samples at month 21 and 35, respectively), 4 liver

24 biopsies (two at month 17, one at month 21 and one post-mortem), and formalin-fixed, 25 paraffin-embedded (FFPE) gallbladder sections from the donor. DNA was extracted using 
1 QIAsymphony instrument (Qiagen, Courtaboeuf, France) or DNAzol (Thermo Scientific,

2 Germany). Viral DNA and cellular loads were quantified using quantitative real-time PCR

3 (qPCR) on LightCycler® 480 system (Roche Diagnostics, Meylan, France) or a

4 StepOnePlus $^{\mathrm{TM}}$ real-time PCR platform (Applied Biosciences, Germany) as previously

5 described to determine the viral copies/mL and copies $/ 10^{6}$ cells. ${ }^{13,14}$ HHV-6 genotyping was

6 performed using qPCR with specific primers. ${ }^{15}$

7

\section{Sequencing of U39, U38 and U69 genes}

The U39 gene encoding glycoprotein B was amplified and sequenced from the liver DNA extracts at month 17 and month 21 as previously described. ${ }^{16}$ Because of the low viral load from whole blood DNA extracts at month 21, only a part of U39 gene from nucleotide 760 to 1154 (395bp) could be amplified and sequenced using gB760 (5'-ctaatgaatggtatgaatggg-3') and gB1154 (5'-agagatttttgcacaagagg-3') primers. The entire U38 (DNA polymerase) and U69 (phosphotransferase) genes encoding the enzymes involved in antiviral resistance were amplified and sequenced from the liver biopsies at month 17 and month 21 as previously described. $^{17}$

\section{Phylogenetic analysis of a part of U39 gene}

The part of U39 sequenced in the transplanted liver and the plasma of the recipient was compared to published sequences of different HHV-6B and iciHHV-6B strains from different countries. ${ }^{7,16,18,19}$ Only the different sequences represented by a reference strain were used to built a phylogenetic tree using the Maximum Likelihood method based on the General Time Reversible model conducted via MEGA7 software (1000 replicates). ${ }^{20,21}$ 


\section{Relative quantification of viral transcripts by retrotranscription (RT) and qPCR}

2 Whole blood was collected using PAXgene Blood RNA tube (PreAnalytix, BD, USA) 35

3 months after transplantation. Liver, spleen and lymph nodes sections from the recipient were

4 collected at autopsy and preserved in RNAlater buffer. RNAs were extracted from blood

5 using the PAXgene Blood RNA kit (Qiagen) and from biopsies using RNeasy extraction kit

6 (Qiagen) after tissue disruption and homogenization on the TissueLyser LT (Qiagen). A

7 whole blood sample from a patient with transiently high HHV-6B reactivation $\left(2.5 \times 10^{6}\right.$

8 DNA copies $/ 10^{6}$ cells) was used as a positive control. PBMCs were isolated by centrifugation

9 in UNI-SEP tube (Eurobio, Courtaboeuf, France) and RNA was extracted using RNeasy extraction kit. For all samples, the residual DNA was removed by treatment with DNase I

11 (Qiagen). The cDNAs were generated by RT in a total volume of $20 \mu \mathrm{L}$ containing $100 \mathrm{ng}$ to

$121 \mu \mathrm{g}$ of extracted RNA, random primers and SuperScriptIII-reverse transcriptase following manufacturer's instructions (Thermo Fisher scientific, Saint-Aubin, France). Negative controls without reverse transcriptase or without RNA extract were included. The cellular $\beta$-actin and viral U38A/B, U42A/B, U94B and U100B cDNAs were then amplified by means of real-time PCR using different primers and MGB-probes, able to amplify both species for U38 and U42 and specific of HHV-6B for U94 and U100 (Table 2). Cross-reaction with HHV-6A transcripts has not been tested and appeared nevertheless possible for U94 because of a lonely mismatch in the forward primer compared to U1102 HHV6-A strain but unlikely for U100 with 10 mismatches in primers and probe. For each amplification system, the amplification

21 efficiencies (AE) were estimated from standard curves established with serial dilutions of cDNAs and were between 1.938 and 1.984. The experiments were performed three to 20

23 times and medians of threshold cycles $(\mathrm{Ct})$ values were calculated for each transcript.

24 Negative results $(\mathrm{Ct}>45)$ for the negative controls validated the specific detection of RNA 25 without DNA contamination. The results were expressed as the relative quantification ratio 
1 (R) of each viral transcript to the positive control with $\beta$-actin as a reference cellular transcript

2 using the formula:

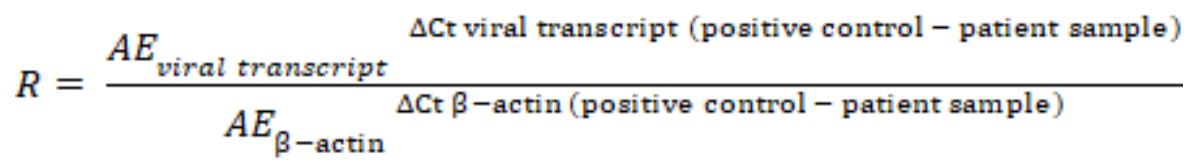

4 This represented the levels of expression of viral genes in the transplanted liver from our 5 patient compared to those expressed in the positive control.

\section{Detection of $\mathrm{gB}$ viral proteins by immunofluorescence assays (IFA)}

8 FFPE post-mortem liver sections from the recipient and gallbladder sections from the donor

9 were studied by immunofluorescence assay. Briefly, FFPE tissue sections were incubated overnight at $55^{\circ} \mathrm{C}$ prior to processing, then deparaffinized using xylene and processed for

11 antigen retrieval using sodium thiocyanate. Subsequently, cell permeabilization was carried 12 out using $0.2 \%$ Triton $\mathrm{X}-100$ for $20 \mathrm{~min}$ at room temperature. Slides were rinsed with 13 phosphate buffered saline (PBS) and blocked for $30 \mathrm{~min}$ in $10 \%$ fetal calf serum (FCS) 14 followed by incubation with a monoclonal antibodies directed against HHV-6A/B late antigen glycoprotein B or HHV-6B specific glycoprotein H (Antibodies clone OHV-1 and clone OHV-3 respectively, obtained from HHV-6 Foundation, USA) in 2\% FCS for 1 hour at room

17 temperature. After washing in PBS, sections were incubated in secondary antibody labeled 18 with Cy3 dye in 2\% FCS containing DAPI. After three washes in PBS, sections were air-dried 19 and mounted with anti-fade medium containing p-Phenylenediamine (P-6001, Sigma). 20 Negative and positive controls were included: non-infected HSB-2 cells, a liver tissue from a 21 4-week male with neonatal hepatitis and a gallbladder tissue from a biliary dyskinesia patient 22 (negative controls), HHV-6A infected HSB-2 cells (positive control for $\mathrm{gB}$, negative control 23 for $\mathrm{gH}$ ) and HHV-6B infected Molt-3 cells (positive controls). All images were captured and 24 analyzed on either a Leica DMR epifluorescence or Leica SP5 confocal microscope. 


\section{RESULTS}

\section{Presence of iciHHV-6B in the liver allograft}

3 PCR performed on hair follicles of the recipient was negative for HHV-6, ruling out iciHHV-

46 in the liver recipient. It was also negative in lymph node biopsies and weakly positive in

5 spleen at the time of death (Table 1). The presence of iciHHV-6 in the transplanted liver was

6 suspected with the first results at month 17 close to the expected viral loads in this case ( $3 \mathrm{x}$

$7 \quad 10^{2}-1.1 \times 10^{3}$ copies $/ 10^{3}$ Eq cells $)$ and persistence along the time $\left(2.6 \times 10^{3}\right.$ to $1.7 \times 10^{4}$

8 copies/mg) (Table 1). Further investigations using different qPCR methods allowing to

9 quantify viral and cellular DNA in four separate liver biopsies as well as in the gallbladder

10 section from the donor (HHV-6B detected) confirmed consistently high HHV-6B DNA loads

$11\left(3.5-4.2 \times 10^{6}\right.$ copies $/ 10^{6}$ cells; Table 1$)$. These results were compatible with the presence of 12 iciHHV-6B in the donor ( $\geq 1$ copy per cell).

13 The DNA load measured in whole blood samples from the recipient was found to be in 14 the range from $6.6 \times 10^{2}$ to $1.6 \times 10^{3}$ copies $/ 10^{6}$ cells. These values expressed as copies per $15 \mathrm{~mL}$ were similar to the corresponding plasma loads: $1.8-3.6 \times 10^{3}$ copies $/ \mathrm{mL}$ of plasma 16 versus $2.0-4.9 \times 10^{3}$ copies/mL of whole blood. The question of a possible reactivation and its 17 source then arose.

Identity of $\mathrm{HHV}-6 \mathrm{~B} \mathrm{U} 39$ sequences in the donor and the recipient

The entire U39 nucleotide sequence of HHV-6 DNA found in the transplanted liver at months 17 and 21 (Seq\#1 [accession number MH680932], Table 1) and the amplified part of 395bp from the blood of the recipient at month 21 (Seq\#1 part) were identical to those of the

23 majority of iciHHV-6B strains ( $\mathrm{n}=77$ including 51 US strains). ${ }^{7,18,19}$ Of note, only seven other 24 published iciHHV-6B (4 US and 3 Asiatic) strains had a different entire U39 sequence. The 25 phylogenetic analysis showed that the same partial sequence was found in 18 community 
1 HHV-6B strains (of which 9 US strains) but was clearly different from those of 74 others

2 including 20 US strains, with one to 10 differences among the 16 single nucleotide 3 polymorphisms (SNPs) highlighted for HHV-6B (Fig. 1A and 1B). ${ }^{7,16,18,19}$ This led us to

4 suggest that the DNA detected in the blood corresponded to iciHHV-6B originated from the $5 \quad$ liver and unlikely from an endogenous community strain. The U38 and U69 genes, encoding the DNA polymerase and the phosphotransferase respectively, were sequenced from liver biopsy samples at months 17 and 21 (Table 1). Both sequences (Seq\#2 [accession number MH680931] and Seq\#3 [accession number MH680933])

11 were identical to those of the laboratory strain MAR which was proven to be sensitive both to ganciclovir and foscarnet in previous susceptibility tests. ${ }^{17}$ Hence, the replication of any HHV-6B strain carrying these sequences, whether it arises from iciHHV-6 reactivation or infection by an exogenous HHV-6 strain, should be sensitive to the action of ganciclovir and foscarnet, making the hypothesis of antiviral resistance unlikely in this case.

\section{Detection of $\mathrm{HHV}-6$ transcripts and proteins}

18 The expression of HHV-6 viral transcripts and proteins was investigated in different clinical samples obtained from the recipient. The HHV-6A/B or $6 \mathrm{~B}$ specific transcripts from immediately early (U94B), early (U38A/B, U42A/B) and late (U100B) viral genes as well as

21 the transcripts from cellular $\beta$-actin gene were searched by real-time RT-PCR in different 22 biopsies and blood samples. While all viral transcripts were detected in a control blood 23 sample from a patient exhibiting a high level HHV-6B reactivation, no viral RNA was 24 detected in the spleen, lymph nodes or whole blood from the recipient (Table 1). U38A/B transcripts were not detected in the transplanted liver. In contrast, U42A/B, U94B and U100B 
1 transcripts were detected in the liver biopsies but inconsistently, the detection frequency being

$27 \%, 50 \%$ and $82 \%$ of assays, respectively. Besides, the levels of expression of the viral genes

3 (R) were low, with $0.06-8.53 \%$ of those in the positive whole blood control with high

4 reactivation. That reflected a viral expression in the liver, but without reaching a level that can

5 be observed in the blood when the lymphocytes produce many infectious particles.

IFA were performed to detect the expression of HHV-6A/B glycoprotein $\mathrm{B}(\mathrm{gB})$ and

7 HHV-6B glycoprotein $\mathrm{H}(\mathrm{gH})$ in recipient and donor tissues. Several cells of the transplanted

8 liver exhibited staining corresponding to expression of $\mathrm{gB}$ and $\mathrm{gH}$ (Fig. 2A and Fig.3A) as

9 well as in the donor gallbladder (Fig. 2B and Fig. 3B). For both glycoproteins, no labeling

was observed in negative control tissues without HHV-6 infection from patients with neonatal

11 hepatitis (liver, Fig. 2C and Fig. 3C) or biliary dyskinesia (gallbladder, Fig. 2D and Fig. 3D).

12 The specificity of the HHV-6A/B staining for $\mathrm{gB}$ was controlled on HHV-6A infected HSB-2

13 cells (Fig. 2F) and HHV-6B infected Molt-3 cells (Fig. 2G) compared to uninfected cells (Fig.

14 2E). The specificity of HHV-6B staining for gH was controlled on HHV-6B infected Molt-3

15 cells (Fig. 3G) compared to uninfected (Fig. 3E) and HHV-6A infected HSB-2 cells (Fig. 3F).

16 These results possibly reflect the pre-existing expression of viral proteins in the donor

17 harboring iciHHV-6B and the continuation of this phenomenon after liver transplantation in 18 the recipient.

\section{DISCUSSION}

21 The reactivation of $\mathrm{HHV}-6 \mathrm{~B}$ is frequently observed in immunocompromised patients, 22 including liver transplant recipients, and can be controlled with antivirals that target DNA 23 replication. In this clinical case, the persistence of HHV-6B DNA in blood and liver biopsies 24 despite treatment with ganciclovir and foscarnet led to the exploration of various hypotheses 25 concerning the pathophysiology of this viral infection. 
The diagnosis of iciHHV-6B in the donor resulted from studies of the allograft where

$2 \geq 1$ copy of HHV-6B genome/cell was found in addition to positive HHV-6 PCR in donor

3 gallbladder sections. Knowledge of iciHHV-6 status of the donor as well as careful

4 monitoring of recipients for evidence of active HHV-6 infection and/or immune organ

5 rejection could help prevent and elucidate the clinical consequences of horizontal

6 transmission of iciHHV-6. ${ }^{3,25}$ Currently, testing for iciHHV-6 is not routinely performed in

7 organ or cell donors, and therefore iciHHV-6 positivity in donor allografts does not preclude

8 transplantation. Further studies are needed to see if iciHHV-6 consistently leads to adverse

9 clinical outcomes and whether there is a role for antiviral prophylaxis or virologic monitoring.

10 With that said, the iciHHV-6 status of the recipient/donor must be considered in cases of high

11 HHV-6 load and possible associated symptoms as the second documented case of horizontal

12 transmission and reactivation of iciHHV- $6 .^{12}$

13 In our case, iciHHV-6 was excluded in the recipient, thus the persistence of HHV-6B

14 infection and its origin were investigated. Although active infection with an endogenous

15 HHV-6B strain following reactivation of a non integrated latent infection in the setting of

16 immune suppression cannot totally be excluded, evidence of intense systemic replication of

17 HHV-6B was weak: the level of HHV-6 DNAemia was low in plasma and whole blood.

18 Given that HHV-6 remains mainly intracellular, even in lytic phase, the viral load should be

19 higher in cellular fraction and whole blood than in plasma in the case of systemic

20 reactivation. ${ }^{26}$ Furthermore, the sequenced part of U39 from DNA in the blood was identical

21 to those in the liver. The phenomenon of release of cell DNA in the blood from an organ has

22 been proven. ${ }^{27}$ In the same way, our results suggest that plasma/whole blood HHV-6B DNA

23 corresponded to viral DNA originated from the lysis of cells contained in the iciHHV-6B+

24 allograft, as a consequence of rejection or immune response to a localized viral infection,

25 rather than a highly active infection of peripheral blood mononuclear cells. Our patient's 
1 HHV-6B reactivation seemed to be restricted mainly to the liver and no clinical symptoms

2 related to the involvement of other organs were reported, which raises additional questions.

3 The circumstantial evidence in favor of iciHHV-6-initiated reactivation, albeit to a modest

4 degree, is based on the similarity of nucleotide sequences between liver and plasma HHV-6B

5 DNA as well as on the detection of U100 transcripts (U94 and U42 transcripts in a lesser

6 extent), HHV-6 glycoprotein B and HHV-6B glycoprotein $\mathrm{H}$ expression in liver tissue. The

7 expression of U94 has been reported in the latent phase of HHV-6 infection or in the context

8 of iciHHV-6 previously. ${ }^{22,23}$ On the other hand, the detection of the late U100 transcript

9 encoding the glycoprotein Q (gp82/105) would suggest that active replication of the virus

10 occurred even in the absence of complete lytic cycle or massive reactivation. ${ }^{24}$ The restriction

11 of active infection within the liver in the recipient supports both hypotheses of iciHHV-6 as

12 the source of active infection and of selective localization of HHV-6 reactivation, which has

13 been suspected to occur in other organs, including the central nervous system of patients with

14 encephalitis and the hearts of patients with myocarditis. ${ }^{28,29}$ Accordingly, the nature of HHV-

15 6B DNA found in plasma remained ambiguous, corresponding to either the trivial release of

16 intracellular HHV-6B DNA when hepatocytes were lysed during inflammatory process or the

17 production of viral particles by actively infected hepatocytes. Persistent HHV-6 infection can

18 cause liver disease in the absence of any evidence in the peripheral blood., ${ }^{2,30}$ Extensive

19 damage to the liver could have occurred before antiviral therapy was administered, which

20 may explain the failure of antivirals in spite of the initial improvement. Testing for

21 corresponding mutations in target viral genes ruled out the possibility of antiviral resistance.

22 The expression of viral proteins from the iciHHV-6B genome present in the liver

23 might have played a role in damaging the graft and triggering graft rejection by boosting

24 inflammatory and immune responses. ${ }^{6}$ It is also possible that the late acute cellular rejection

25 might have stimulated a local HHV-6 reactivation. Additionally, steroid therapy can 
1 exacerbate active HHV-6 infection, ${ }^{2}$ rendering antiviral therapy less effective and extended

2 antiviral treatment may have contributed to the patient's deterioration. HHV-6 mRNA assays

3 are available at a small number of specialized commercial laboratories in the US and in

4 Europe, and immunohistochemistry analysis of liver biopsies for late proteins can assist

5 physicians in determining whether HHV-6 specific antiviral therapy might be useful.

6 This case is the first description of a possible localized reactivation of iciHHV-6B in a

7 liver transplant patient associated with subsequent acute rejection, supporting the need for

8 further studies regarding the medical impact of iciHHV-6 on organ transplantation and

9 perhaps to include HHV-6 testing for the qualification of the donors.

\section{Acknowledgments}

12 We thank Kristin Loomis and the HHV-6 Foundation for assistance in facilitating the testing

13 of samples in specialty laboratories and supporting this work. We also thank Dr. Michelle 14 Altrich from Viracor Eurofins for the exchanges and clarifications made. 
2 1. Agut H, Bonnafous P, Gautheret-Dejean A. Laboratory and clinical aspects of human

3 herpesvirus 6 infections. Clin Microbiol Rev. 2015;28(2):313-35.

4 2. Phan TL, Lautenschlager I, Razonable RR, Munoz FM. HHV-6 in liver transplantation: A $5 \quad$ literature review. Liver Int. 2018;38(2):210-23.

6 3. Pellett PE, Ablashi DV, Ambros PF, et al. Chromosomally integrated human herpesvirus 6:

7 questions and answers. Rev Med Virol. 2012;22(3):144-55.

4. Tweedy J, Spyrou MA, Pearson M, Lassner D, Kuhl U, Gompels UA. Complete Genome

9 Sequence of Germline Chromosomally Integrated Human Herpesvirus 6A and Analyses Integration Sites Define a New Human Endogenous Virus with Potential to Reactivate as an

11 Emerging Infection. Viruses. 2016;8(1): E19.

12 5. Gravel A, Dubuc I, Morissette G, Sedlak RH, Jerome KR, Flamand L. Inherited 13 chromosomally integrated human herpesvirus 6 as a predisposing risk factor for the 14 development of angina pectoris. Proc Natl Acad Sci U S A. 2015;112(26):8058-63.

15 6. Hill JA, Magaret AS, Hall-Sedlak R, et al. Outcomes of hematopoietic cell transplantation 16 using donors or recipients with inherited chromosomally integrated HHV-6. Blood. $17 \quad 2017 ; 130(8): 1062-9$.

18 7. Zhang E, Bell AJ, Wilkie GS, et al. Inherited Chromosomally Integrated Human 19 Herpesvirus 6 Genomes Are Ancient, Intact, and Potentially Able To Reactivate from 20 Telomeres. J Virol. 2017;91(22): e01137-17.

21 8. Miura H, Kawamura Y, Hattori F, et al. Chromosomally integrated human herpesvirus 6 in 22 the Japanese population. J Med Virol. 2018;90(10):1636-42.

23 9. Komaroff AL, Phan T, Flamand L, Pellett PE. Summary of the 9th international conference 24 on human herpesviruses 6 and 7 (HHV-6A, HHV-6B, and HHV-7). J Med Virol. $25 \quad 2016 ; 88(12): 2038-43$. 
1 10. Endo A, Watanabe K, Ohye $\mathrm{T}$, et al. Molecular and virological evidence of viral

2 activation from chromosomally integrated human herpesvirus $6 \mathrm{~A}$ in a patient with $\mathrm{X}$-linked

3 severe combined immunodeficiency. Clin Infect Dis. 2014;59(4):545-8.

4 11. Sedlak RH, Hill JA, Nguyen T, et al. Detection of Human Herpesvirus 6B (HHV-6B)

5 Reactivation in Hematopoietic Cell Transplant Recipients with Inherited Chromosomally

6 Integrated HHV-6A by Droplet Digital PCR. J Clin Microbiol. 2016;54(5):1223-7.

7 12. Bonnafous $\mathrm{P}$, Marlet $\mathrm{J}$, Bouvet $\mathrm{D}$, et al. Fatal outcome after reactivation of inherited

8 chromosomally integrated HHV-6A (iciHHV-6A) transmitted through liver transplantation.

$9 \quad$ Am J Transplant. 2018;18(6):1548-51.

13. Gautheret-Dejean A, Manichanh C, Thien-Ah-Koon F, et al. Development of a real-time

11 polymerase chain reaction assay for the diagnosis of human herpesvirus-6 infection and 12 application to bone marrow transplant patients. J Virol Methods. 2002;100(1-2):27-35.

13 14. Prusty BK, Siegl C, Hauck P, et al. Chlamydia trachomatis infection induces replication of 14 latent HHV-6. PloS One. 2013;8(4):e61400.

15 15. Boutolleau D, Duros C, Bonnafous P, et al. Identification of human herpesvirus 6 variants 16 A and B by primer-specific real-time PCR may help to revisit their respective role in 17 pathology. J Clin Virol.2006;35(3):257-63.

18 16. Achour A, Malet I, Le Gal F, et al. Variability of $\mathrm{gB}$ and gH genes of human herpesvirus196 among clinical specimens. J Med Virol. 2008;80(7):1211-21.

20 17. Manichanh C, Olivier-Aubron C, Lagarde JP, et al. Selection of the same mutation in the 21 U69 protein kinase gene of human herpesvirus-6 after prolonged exposure to ganciclovir in 22 vitro and in vivo. J Gen Virol. 2001;82(11):2767-76.

23 18. Telford M, Navarro A, Santpere G. Whole genome diversity of inherited chromosomally 24 integrated HHV-6 derived from healthy individuals of diverse geographic origin. Sci Rep. $25 \quad 2018 ; 8(1): 3472$ 
1 19. Greninger AL, Knudsen GM, Roychoudhury P, et al. Comparative genomic,

2 transcriptomic, and proteomic reannotation of human herpesvirus 6. BMC Genomics. $3 \quad 2018 ; 19(1): 204$.

4 20. Nei M. and Kumar S. (2000). Molecular Evollution and Phylogenetics. Oxford University

5 Press, New York

6 21. Kumar S., Stecher G., and Tamura K. (2016). MEGA7: Molecular Evolutionary Genetics

7 Analysis version 7.0 for bigger datasets. Molecular Biology and evolution 33:1870-1874.

22. Rotola A, Ravaioli T, Gonelli A, Dewhurst S, Cassai E, Di Luca D. U94 of human

9 herpesvirus 6 is expressed in latently infected peripheral blood mononuclear cells and blocks

10 viral gene expression in transformed lymphocytes in culture. Proc Natl Acad Sci U S A. $11 \quad 1998 ; 95(23): 13911-6$.

12 23. Strenger V, Urban C, Schwinger W, Nacheva EP, Aberle SW. Transmission of 13 chromosomally integrated HHV-6 by bone marrow transplantation. Pediatr Blood Cancer. $14 \quad 2011 ; 56(1): 171$.

24. Mirandola P, Menegazzi P, Merighi S, Ravaioli T, Cassai E, Di Luca D. Temporal mapping of transcripts in herpesvirus 6 variants. J Virol. 1998;72(5):3837-44.

25. Flamand L. Pathogenesis from the reactivation of chromosomally integrated human 18 herpesvirus type 6: facts rather than fiction. Clin Infect Dis. 2014;59(4):549-51.

19 26. Achour A, Boutolleau D, Slim A, Agut H, Gautheret-Dejean A. Human herpesvirus-6 (HHV-6) DNA in plasma reflects the presence of infected blood cells rather than circulating

21 viral particles. J Clin Virol. 2007;38(4):280-5.

22 27. van der Vaart M, Pretorius PJ. The origin of circulating free DNA. Clin Chem. $23 \quad 2007 ; 53(12): 2215$.

24 28. Caserta MT, Dewhurst S. Dazed and confused by HHV-6. Blood. 2011;117(19):5016-8. 
1 29. Leveque N, Boulagnon C, Brasselet C, et al. A fatal case of Human Herpesvirus 6 chronic

2 myocarditis in an immunocompetent adult. J Clin Virol. 2011;52(2):142-5.

3 30. Buyse S, Roque-Afonso A-M, Vaghefi P, et al. Acute Hepatitis With Periportal Confluent

4 Necrosis Associated With Human Herpesvirus 6 Infection in Liver Transplant Patients. Am J

$5 \quad$ Clin Pathol. 2013;140(3):403-9.

6

7

8

9

10

11

12

13

14

15

16

Figures Legends

Figure 1. Molecular phylogenetic analysis of a part of U39 from HHV-6B and iciHHV-6B strains.

The part of U39 gene from nucleotide 760 to 1154 (Seq\#1part, 395bp) sequenced in the transplanted liver and the plasma of the recipient (TCH-B1 US) was compared to published sequences of different HHV-6B and iciHHV-6B strains from different countries. ${ }^{7,16,18,19}$ (A)

The Maximum Likelihood phylogenetic analysis was conducted via MEGA7 (1000 replicates, bootstrap values indicated for each node) with General Time Reversible model using only different sequences represented by a reference strain $^{20,21}$ (B) the single nucleotide polymorphisms (SNPs) among the different reference strains are detailed, as well as the total number of published strains sharing these sequences (including US strains).

Figure 2. Immunolfluorescence assays on formalin fixed paraffin embedded (FFPE) tissues and cells using the anti-HHV-6A/B gB antibody OHV-1.

(A) Transplanted liver of the recipient, the arrows indicate the gB labelling; (B) gallbladder from the donor; (C) liver from a 4-week male with neonatal hepatitis (negative control); (D) gallbladder tissue from a biliary dyskinesia patient (negative control); (E) uninfected HSB-2 cells (negative control); (F) HHV-6A infected HSB-2 cells (positive control); (G) HHV-6B 
1 infected Molt-3 cells (positive control). Cell nuclei were labeled in blue (DAPI) and HHV-

$26 \mathrm{~A} / \mathrm{B} \mathrm{gB}$ in red (Cy3). Images were captured either by epifluorescence microscopy (A-C) or

3 confocal microscopy (D-G) with a 10X magnification.

4

5 Figure 3. Immunofluorescence assays on formalin fixed paraffin embedded (FFPE) tissues 6 and cells using the anti-HHV-6B gH antibody OHV-3.

7 (A) Transplanted liver of the recipient, the arrow indicates the higher magnification; (B)

8 gallbladder from the donor; (C) liver from a 4-week male with neonatal hepatitis (negative

9 control); (D) gallbladder tissue from a biliary dyskinesia patient (negative control); (E)

10 uninfected HSB-2 cells (negative control); (F) HHV-6A infected HSB-2 cells (negative

11 control); (G) HHV-6B infected Molt-3 cells (positive control). Cell nuclei were labeled in

12 blue (DAPI) and HHV-6B $\mathrm{gH}$ in red (Cy3). Images were captured either by confocal

13 microscopy (A, D-G) or epifluorescence microscopy $(B, C)$ with a 10X magnification. 
1 Table 1: Results of various laboratory investigations

\begin{tabular}{|c|c|c|c|c|c|c|c|c|}
\hline \multirow{2}{*}{$\begin{array}{c}\text { Time after } \\
\text { transplantation }\end{array}$} & \multirow{2}{*}{$\begin{array}{c}\text { Biological } \\
\text { sample type }^{\text {a }}\end{array}$} & \multirow{2}{*}{ HHV-6 viral load } & \multicolumn{3}{|c|}{ HHV-6 sequencing } & \multirow{2}{*}{$\begin{array}{l}\text { HHV-6 transcripts detected } \\
\text { (frequency); R: relative } \\
\text { quantification ratio of viral } \\
\text { genes to the positive control }\end{array}$} & \multicolumn{2}{|c|}{ Protein detection } \\
\hline & & & U39 & U38 & U69 & & $\begin{array}{c}\text { HHV-6A/B } \\
\text { gB }\end{array}$ & $\begin{array}{c}\text { HHV-6B } \\
\text { gH }\end{array}$ \\
\hline $\mathrm{n} / \mathrm{a}$ & $\begin{array}{l}\text { Recipient hair } \\
\text { follicles }\end{array}$ & Undetectable & - & - & - & - & - & - \\
\hline \multirow[b]{2}{*}{ Month +17} & Plasma & $4.7 \times 10^{3}-1.4 \times 10^{4}$ copies $/ \mathrm{mL}^{\mathrm{b}}$ & - & - & - & - & - & - \\
\hline & Liver biopsy & $\begin{array}{c}3 \times 10^{2}-1.1 \times 10^{3} \text { copies } / 10^{3} \mathrm{Eq} \text { cells } \\
3.9-4.2 \times 10^{6} \text { copies } / 10^{6} \text { cells }^{\mathrm{c}}\end{array}$ & ; Seq\#1 & $\begin{array}{c}\text { Seq\#2 } \\
(\text { HHV-6B) }\end{array}$ & $\begin{array}{c}\text { Seq\#3 } \\
(\text { HHV-6B) }\end{array}$ & - & - & - \\
\hline Month +18 to +21 & Plasma & $2.1-8.9 \times 10^{3}$ copies $/ \mathrm{mL}^{\mathrm{b}}$ & - & - & - & - & - & - \\
\hline \multirow{3}{*}{ Month $+21^{\mathrm{d}}$} & Plasma & $2.1 \times 10^{3}$ copies $/ \mathrm{mL}^{\mathrm{b}}$ & - & - & - & - & - & - \\
\hline & Whole blood & $\begin{array}{c}3.6 \times 10^{3} \text { copies } / \mathrm{mL}^{\mathrm{c}} \\
1.1 \times 10^{3} \text { copies } / 10^{6} \text { cells }^{\mathrm{c}}\end{array}$ & $\begin{array}{c}\text { Seq\#1part } \\
\text { (HHV-6B) }\end{array}$ & - & - & - & - & - \\
\hline & Liver biopsy & $\begin{array}{l}1.5-1.7 \times 10^{4} \text { copies } / \mathrm{mg}^{\mathrm{b}} \\
4.1 \times 10^{6} \text { copies } / 10^{6} \text { cells }\end{array}$ & $\begin{array}{c}\text { Seq\#1 } \\
(\mathrm{HHV}-6 \mathrm{~B})\end{array}$ & $\begin{array}{c}\text { Seq\#2 } \\
(\text { HHV-6B) }\end{array}$ & $\begin{array}{c}\mathrm{Seq \# 3} \\
(\mathrm{HHV}-6 \mathrm{~B})\end{array}$ & - & - & - \\
\hline Month +22 to +35 & Plasma & $1 \times 10^{2}-3.2 \times 10^{4}$ copies $/ \mathrm{mL}^{\mathrm{b}}$ & - & - & - & - & - & - \\
\hline \multirow[b]{2}{*}{ Month $+35^{\mathrm{d}}$} & Plasma & $1.8-3.6 \times 10^{3}$ copies $/ \mathrm{mL}^{\mathrm{b}}$ & - & - & - & - & - & - \\
\hline & Whole blood & $\begin{array}{c}2.0-4.9 \times 10^{3} \text { copies } / \mathrm{mL}^{\mathrm{c}} \\
6.6 \times 10^{2}-1.6 \times 10^{3} \text { copies } / 10^{6} \text { cells }^{\mathrm{c}} \\
\end{array}$ & - & - & - & All undetectable & - & - \\
\hline \multirow[b]{3}{*}{$\begin{array}{c}\text { Month }+36 \\
\text { (Post-mortem) }\end{array}$} & Lymph nodes & Undetectable $(<8 \text { copies } / \mathrm{mg})^{\mathrm{b}}$ & - & - & - & All undetectable & - & - \\
\hline & Spleen & 38 copies $/ \mathrm{mg}^{\mathrm{b}}$ & - & - & - & All undetectable & - & - \\
\hline & Liver biopsy & $\begin{array}{l}2.6 \times 10^{3} \text { copies } / \mathrm{mg}^{\mathrm{b}} \\
3.5 \times 10^{6} \text { copies } / 10^{6} \text { cells }\end{array}$ & - & - & - & $\begin{array}{l}\text { U100B detected (82\%); R: } 8.53 \% \\
\text { U94B detected (50\%); R: } 0.34 \% \\
\text { U42A/B detected (7\%); R: } 0.06 \% \\
\text { U38A/B undetected }\end{array}$ & Positive & Positive \\
\hline $\mathrm{n} / \mathrm{a}$ & $\begin{array}{l}\text { Donor } \\
\text { gallbladder }\end{array}$ & $3.9 \times 10^{6}$ copies $/ 10^{6}$ cells $^{\mathrm{e}}$ & - & - & - & - & Positive & Positive \\
\hline
\end{tabular}


1 n/a, not applicable; -, not performed; ${ }^{a}$ all biological samples were from the recipient, except the donor gallbladder; ${ }^{\mathrm{b}}$ quantified by Viracor

2 Eurofins; ${ }^{\mathrm{c}}$ quantified in French laboratory using previously described method ${ }^{13} ;{ }^{\mathrm{d}}$ plasma and whole blood was sampled at the same time; ${ }^{\mathrm{e}}$

3 quantified in German laboratory using previously described method ${ }^{14}$.

4 Viral genes U39, U38 and U69 encode the glycoprotein B, the DNA polymerase and the phosphotransferase, respectively. Seq\#1 (total gene: 52493 nucleotides) was identical to those of all except 7 iciHHV-6B strains. ${ }^{7,18,19}$ Seq\#1part was the sequence of Seq\#1 from 760 to 1154 6 nucleotide. Seq\#2 and Seq\#3 were identical to those of the MAR strain, sensitive to antivirals. ${ }^{17}$ Seq\#1, Seq\#2 and Seq\#3 are within the 7 accession numbers MH680932, MH680931, and MH680933, respectively. The frequency of transcripts detection among tested is expressed in 8 percentage. The relative quantification ratio (R) represents the level of expression of each viral gene (U38A/B and U42A/B, U94B and U100B)

9 compared to this expressed in the whole blood of a positive control exhibiting a high level HHV-6B reactivation. 
1 Table 2. Primers and probes (5'-3') used for the detection of cellular and viral transcripts

\begin{tabular}{llll}
\hline $\begin{array}{l}\text { Transcripts } \\
\text { (spliced or not) }\end{array}$ & Forward primer & Reverse primer & Probe (FAM-MGB) \\
\hline$\beta$-actin (spliced) & BAF1: ccagctcaccatggatgatg & BAR1: atgccggagccgttgtc & BAp1: tatcgccgcgctcg \\
U38A/B & U38Ft1: tgtgactctgaaccgcgtatg & U38Rt1: aaactcggccaagtcatttcttt & U38p1: cgagaccgacagtatt \\
U42A/B & U42Ft1: tgcaggcttcttctactgtagca & U42Rt1: cggatattctcctgaccaact & U42p1: ctgtaaaagcaagacaagg \\
U94B & U94Ft1B: tccgccaccattttctttg & U94Rt1: ggaacgcccctaaaatagatga & U94p1: tttggcatacgtgcacca \\
U100B (spliced) & U100Ft1B: tcaagagttcgatattgacgatcag & U100Rt1B: tggagctacgccaaaactacaga & U100p1B: catcgagccttttc \\
\hline
\end{tabular}




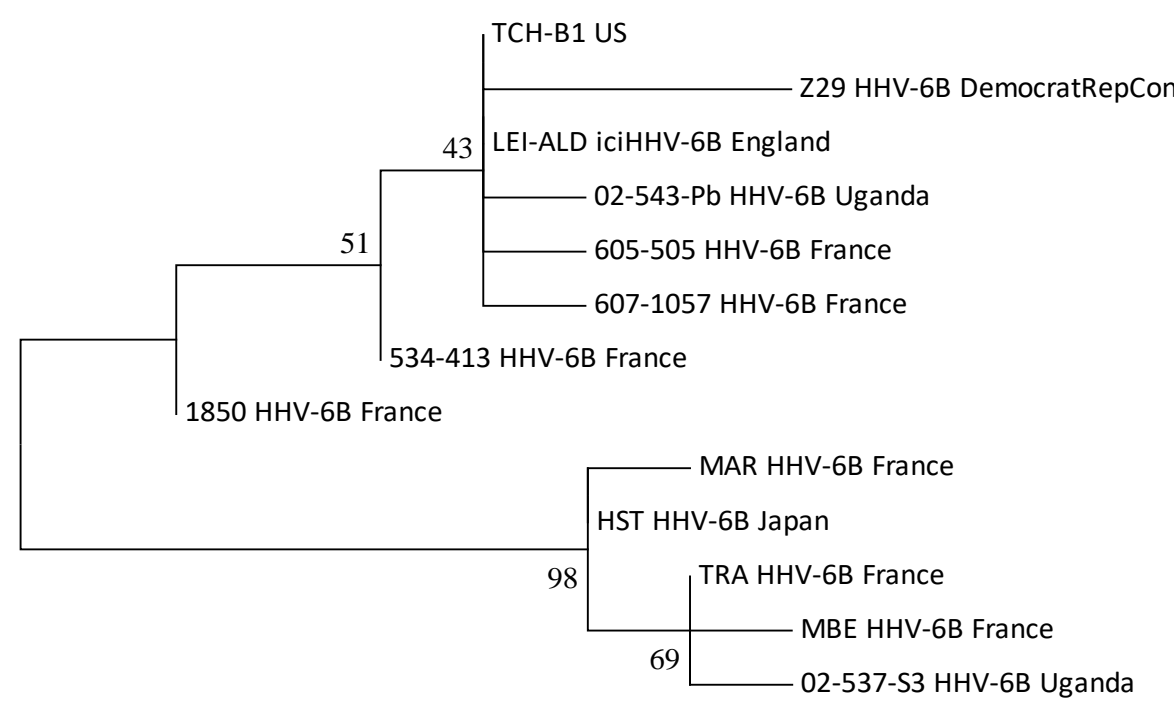

0.0020

Reference strain

SNPs in part of U39 (760-1154)

Total number of published strains

(US strains)

\begin{tabular}{|c|c|c|c|c|c|c|c|c|c|c|c|c|c|c|c|c|c|}
\hline TCH-B1_US (Seq\#1 part) & G & $\mathrm{T}$ & G & $\mathrm{C}$ & G & G & $\mathrm{T}$ & G & $\mathrm{T}$ & G & $\mathrm{C}$ & $\mathrm{T}$ & G & $A$ & $\mathrm{C}$ & $A$ & \\
\hline LEI_iciHHV-6B_England & - & - & - & - & - & - & - & - & - & - & - & - & - & - & - & - & 18 (9) HHV-6B, 79 (56) iciHHV-6B \\
\hline 02-543-Pb_HHV-6B_Uganda & - & - & - & - & - & - & - & - & - & - & - & - & A & - & - & - & $1(0)$ HHV-6B \\
\hline 605-505_HHV-6B_France & - & - & - & $\mathrm{T}$ & - & - & - & - & - & - & - & - & - & - & - & - & $1(0)$ HHV-6B \\
\hline 607-1057_HHV-6B_France & - & $\mathrm{C}$ & - & - & - & - & - & - & - & - & - & - & - & - & - & - & $2(0)$ HHV-6B \\
\hline 534-413_HHV-6B_France & $\mathrm{C}$ & - & - & - & - & - & - & - & - & - & - & - & - & - & - & - & $1(0)$ HHV-6B \\
\hline Z29_HHV-6B_DemocratRepCongo & - & - & - & - & - & - & - & - & - & - & - & - & - & G & A & $\mathrm{C}$ & $1(0)$ HHV-6B \\
\hline 1850_HHV-6B_France & $\mathrm{C}$ & $\mathrm{C}$ & - & $\mathrm{T}$ & - & - & - & - & - & - & - & - & - & - & - & - & $1(0)$ HHV-6B \\
\hline MAR_HHV-6B_France & $\mathrm{C}$ & - & - & $\mathrm{T}$ & - & A & C & $\mathrm{T}$ & $\mathrm{C}$ & $\mathrm{T}$ & A & A & - & - & - & - & $1(0)$ HHV-6B \\
\hline HST_HHV-6B_Japan & $\mathrm{C}$ & $\mathrm{C}$ & - & $\mathrm{T}$ & - & $A$ & $\mathrm{C}$ & $\mathrm{T}$ & $\mathrm{C}$ & $\mathrm{T}$ & $A$ & $A$ & - & - & - & - & 36 (7) HHV-6B, 2 (1) iciHHV-6B \\
\hline TRA_HHV-6B_France & $\mathrm{C}$ & $\mathrm{C}$ & - & - & - & $A$ & $\mathrm{C}$ & $\mathrm{T}$ & $\mathrm{C}$ & $\mathrm{T}$ & $A$ & A & - & - & - & - & 24 (10) HHV-6B, 3 (1) iciHHV-6B \\
\hline MBE_HHV-6B_France & $\mathrm{C}$ & $\mathrm{C}$ & $\mathrm{A}$ & - & - & $\mathrm{A}$ & $\mathrm{C}$ & $\mathrm{T}$ & $\mathrm{C}$ & $\mathrm{T}$ & $\mathrm{A}$ & $\mathrm{A}$ & - & - & - & - & $5(3)$ HHV-6B \\
\hline 02-537-S3_HHV-6B_Uganda & $\mathrm{C}$ & $\mathrm{C}$ & - & - & $\mathrm{T}$ & $A$ & $\mathrm{C}$ & $\mathrm{T}$ & $\mathrm{C}$ & $\mathrm{T}$ & $A$ & $A$ & - & - & - & - & 1 (0) HHV-6B \\
\hline
\end{tabular}

Figure 1. 

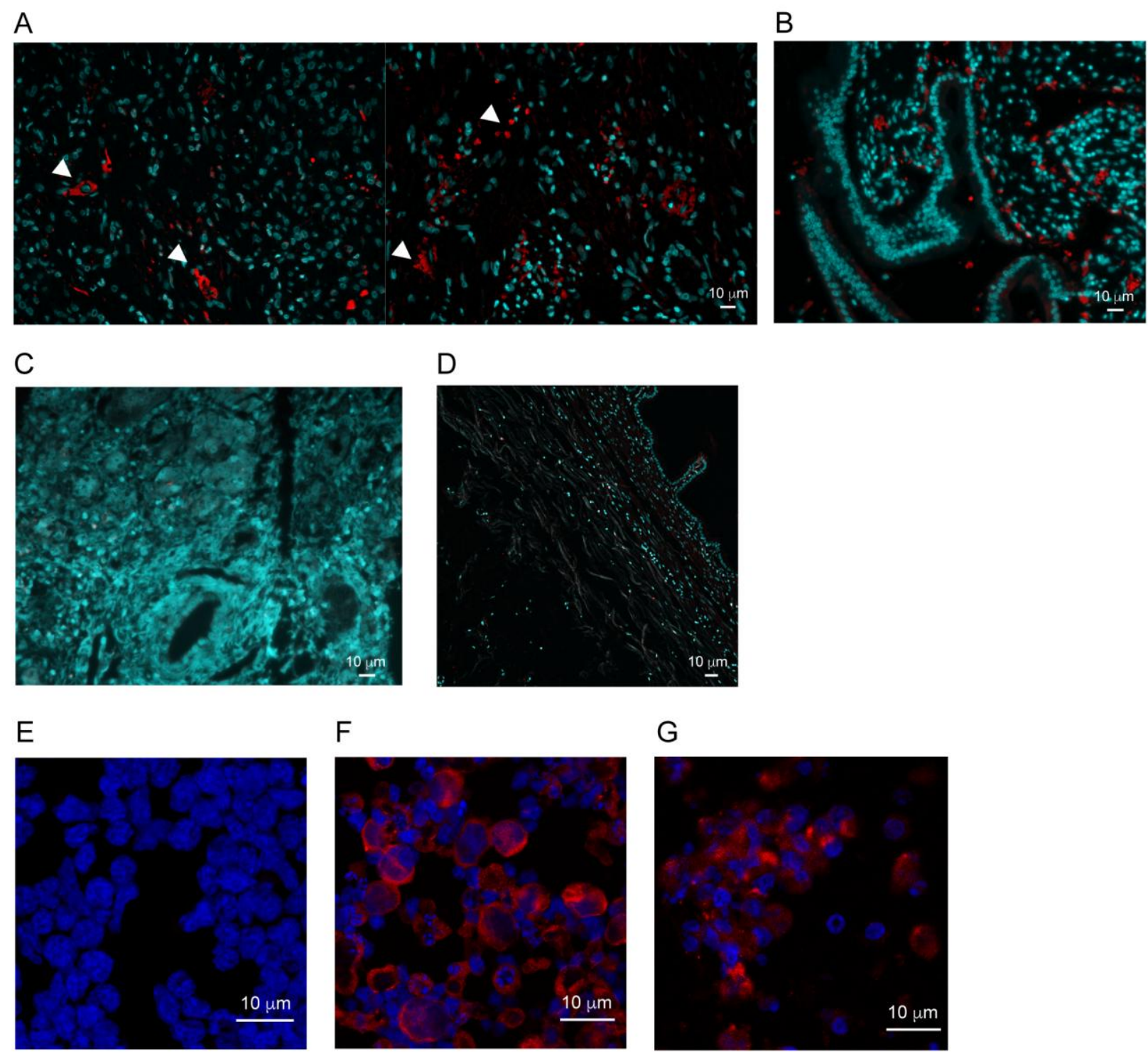

Figure 2. 


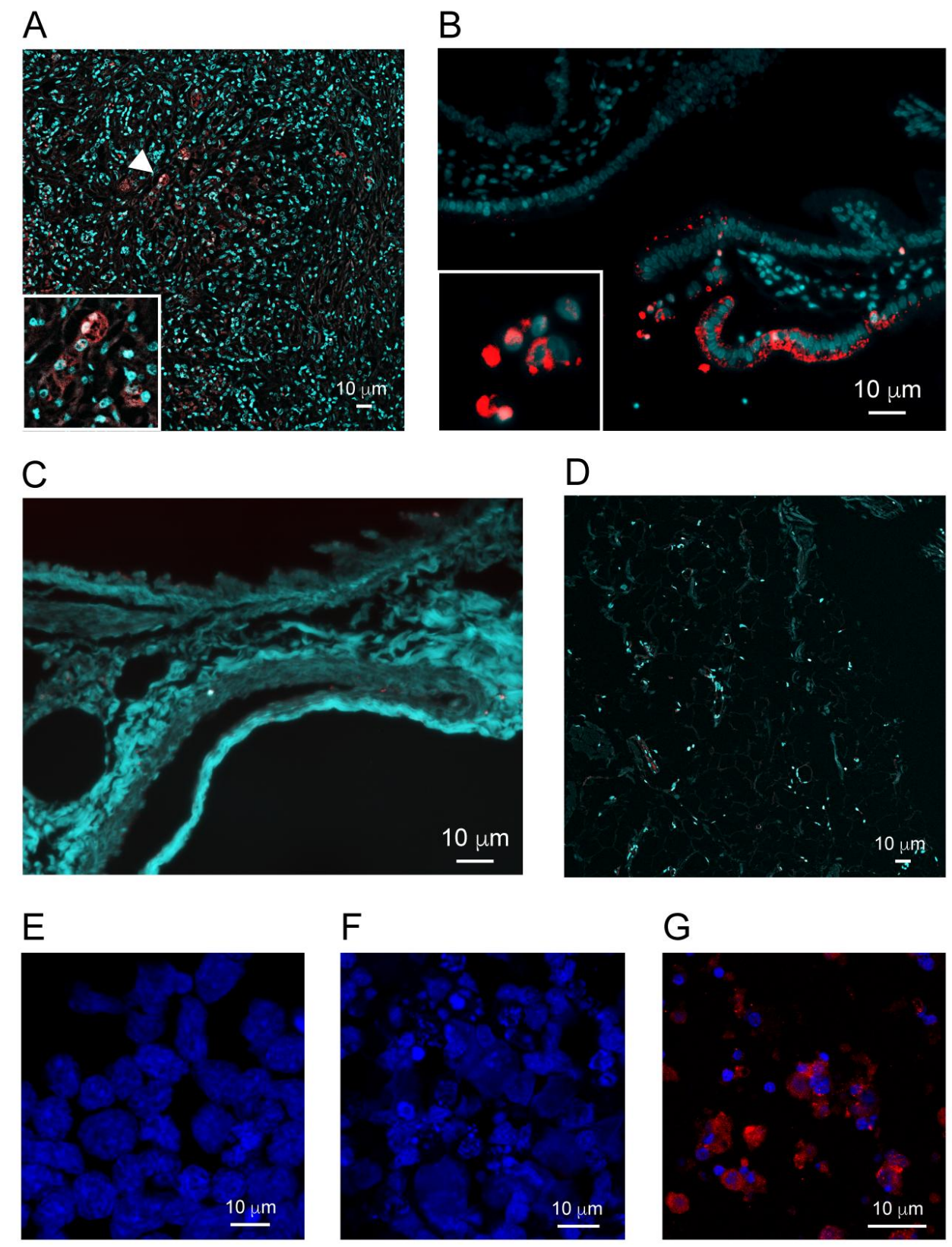

Figure 3. 